\title{
Biocontrol of Pythium aphanidermatum causing soft rot in ginger with biosurfactant produced by a rhizospheric Bacillus species
}

\author{
D Goswami* \& M B Syiem \\ Department of Biochemistry, North-Eastern Hill University, Shillong-793 022, Meghalaya. \\ *E-mail: debahutig@rediffmail.com
}

Received 13 November 2020; Revised 29 April 2021; Accepted 09 May 2021

\begin{abstract}
Plant growth-promoting rhizobacteria benefit plants by producing phytohormones and acquiring vital nutrients from soil. They also form a shield against potential phytopathogens with the production of antimicrobial compounds such as bacteriocin, biosurfactants etc. In the present study, among various rhizobacteria isolated from ginger rhizosphere, the isolate identified as Bacillus altitudinis VS7 that showed a potent biosurfactant producing ability in the preliminary tests was selected for the further study. Compositional analyses indicated that the biosurfactant produced by VS7 was a surfactin like compound, a cyclic lipopeptide. In both microtitre plate and mycelium growth inhibition studies, the biosurfactant showed dose dependent antagonistic activities against Pythium aphanidermatum that causes soft rot in ginger. Although there are reports of biocontrol activity of various rhizobacteria against soft rot in ginger, this is the first information regarding biocontrol activity of a biosurfactant produced by the rhizobacterium B. altitudinis VS7 against $P$. aphanidermatum.
\end{abstract}

Keywords: Bacillus altitudinis VS7, biocontrol, biosurfactant, plant probiotics, Pythium aphanidermatum, rhizobacteria

\section{Introduction}

Plant probiotics are the beneficial microorganisms that aids in nutritional and health-promoting benefits on plants. The benefits of inoculating plant probiotics in agricultural crops comprise growth in yield, chlorophyll and protein content, nutrient uptake, improvement in soil health, biocontrol, etc. Plant growth-promoting rhizobacteria (PGPR) possess the ability to improve plant growth and productivity as they provide various essential nutrients (micro as well as macronutrients) to plants. Various researchers in agriculture currently are aimed at understanding the correlation amongst plants and probiotics (Gosal et al. 2017). It is now established that PGPR are appropriate as probiotics for agriculture because of their role in promoting plant growth and productivity in a sustainable and environment friendly approach, thus decreasing dependency on chemical fertilizers. Additionally, they protect plants from diseases and various types of 
stresses. They facilitate the plant growth directly by helping in acquisition of essential nutrients and production of phytohormones or indirectly by acting as biocontrol agent. PGPR now have been accepted worldwide as plant probiotics because of their ability to act as biocontrol agents and biofertilizer for promoting healthy growth in plants with which they are associated (Gosal et al. 2017).

Some PGPRs produce biosurfactant, however, a handful of reports are available in literature about the occurrence of microbes that produce biosurfactant in the rhizospheric soil of different plants (Goswami \& Deka 2019). Malfanova et al. (2011) reported a plant-beneficial endophytic strain Bacillus subtilis HC8 from a giant hogweed Heracleum sosnowskyi Manden that protects tomato against foot and root rot and thus extensively promotes plant growth. Later, they found that the strain B. subtilis HC8 produced three major families of cyclic lipopeptide- that is a type of biosurfactant. Biosurfactants are structurally varied group of surface active biochemical compounds comprising of hydrophilic and hydrophobic moieties formed on living surfaces, predominantly on cell surfaces of microbes, or secreted extracellularly (Rahman \& Gakpe 2008). They have been acclaimed gradually as an alternative to synthetic ones as they possess the characteristics such as low toxicity, biodegradability, better environmental compatibility, higher foaming, high selectivity, and specific activity under extreme conditions such as temperature, $\mathrm{pH}$, and salinity. Biosurfactants have wide range of applications in various pharmaceutical/medicine, food, agriculture, cosmetic, pesticide, oil, and biodegradation industries (Shekhar et al. 2015).

Ginger (Zingiber officinale Roscoe) is cultivated worldwide as cash crop all through the tropics and subtropics. In India, Meghalaya is one of the leading ginger producing state in northeastern region. Recent awareness on antiinflammatory, antibacterial and antifungal properties of ginger has drawn extensive attention in the farming community (Le et al.
2014). However, ginger is prone to different plant pathogens; of these soft rot or rhizome rot is a notable disease of ginger in India that causes more than $80 \%$ annual loss of the crop (Sarma 1994). Among several species of the oomycete pathogen, Pythium aphanidermatum is the most predominant and extensively dispersed species that is associated with soft rot (Dake \& Edison 1989). P. aphanidermatum is a soil borne pathogen and its infection originates at the collar region of the pseudostem that extends into the rhizome initiating degeneration of the entire inner tissues. The severity of the infection is such that even after harvesting, the rotting can continue during storage period (Mahanta \& Samajdar 2013).

Soft rot of ginger is very complicated to manage (Kavitha \& Thomas 2007). Various approaches involving cultural, biological, chemical, and induced resistance have been studied to gain control over the disease. In one such study, Bhai et al. (2005) stated that the application of PGPR and vesicular arbuscular mycorrhizae has been successful in inhibiting ginger soft rot. Amongst the PGPR, Bacillus sp. and Pseudomonas fluorescens Migula were shown to be efficient for biocontrol of soft rot due to their rhizosphere competence. Sarwar et al. (2018) in their study observed that the lipopeptide biosurfactant of Bacillus spp. exhibited proficient activity against several phytopathogens, for example against Fusarium oxysporum that causes root rot, and Fusarium moniliforme that initiates rice bakanae disease etc. Ongena et al. (2005) demonstrated the role of lipopeptides secreted by Bacillus subtilis strain M4, against damping-off of bean seedlings caused by Pythium ultimum. However, activity of lipopeptide biosurfactant produced by Bacillus sp. against soft rot of ginger has not been reported earlier. Further, there are limited reports in the past relating to production of biosurfactant by plant-associated bacteria. Thus, the current study was performed by aiming to appraise the effectiveness of lipopeptide biosurfactant produced by ginger rhizospheric Bacillus species as prospective antagonistic plant probiotic agent to control 
ginger soft rot initiated by P. aphanidermatum.

\section{Materials and methods \\ The pathogen}

The phytopathogen Pythium aphanidermatum strain 3482 was procured from NFCCI (National Fungal Culture Collection of India), Agharkar Research Institute, Pune, India. It was stored as microconidial suspensions in 30\% glycerol at $-80^{\circ} \mathrm{C}$ (Borah et al. 2016). Potato dextrose agar (PDA; HiMedia) plates and Potato dextrose broth (PDB; HiMedia) at $4^{\circ} \mathrm{C}$ were used to maintain the working cultures which were subcultured every 2 weeks.

Selection of antagonistic bacterial isolates to $P$. aphanidermatum

The probable antagonistic beneficial bacteria, i.e., probiotics were isolated from rhizosphere soil as well as surrounding soil of ginger roots collected from Ginger Development Station $\left(25^{\circ} .43^{\prime} \mathrm{N}\right.$ to $25^{\circ} 43^{\prime} \mathrm{N}$ latitudes and $53^{\prime} \mathrm{E}$ to $92^{\circ} 0^{\prime}$ E longitudes), Umsning, Meghalaya. To isolate bacteria, soil sample (10 g) was added to $90 \mathrm{ml}$ of $0.9 \%$ sodium chloride and serially diluted to $10^{-4}$. Then $100 \mu \mathrm{l}$ of the diluted sample was spread into nutrient agar (NA; HiMedia) plates. Subsequent to the incubation of the plates at $35^{\circ} \mathrm{C}$ for $24 \mathrm{~h}$, morphologically distinct individual bacterial colonies appeared on plates. Again streaking of the colonies were performed on NA plates to achieve pure cultures, and later maintained on NA slants and Nutrient broth (NB; HiMedia) kept at $4^{\circ} \mathrm{C}$.

Evaluation of the bacteria for antagonism against $P$. aphanidermatum was accomplished in vitro using dual culture method on PDA plates. Briefly, agar blocks $(5 \mathrm{~mm})$ having 5 days old mycelia of $P$. aphanidermatum were put at the center of each of the PDA plate and the bacterial isolate was streaked with a space of $2 \mathrm{~cm}$ from the mycelial plug. Plates without the bacterial isolate served as controls. All the plates were incubated at $28 \pm 2^{\circ} \mathrm{C}$ for 5 days or until the leading edge of the mycelia in the control plate touched the verge of the plate (Raghavan et al. 2015). The percentage of growth inhibition was determined with the formula: C-T/C x 100, where $C$ is the colony growth of pathogen in control plate, and $\mathrm{T}$ is the colony growth of pathogen in dual culture, i.e., the plate with P. aphanidermatum and bacterial isolate (Sumbhe $\&$ Tomar 2015). The experiment was performed with three replications and was repeated three times.

Screening of antagonistic rhizospheric bacteria for biosurfactant producing properties

To conduct the screening, the isolates were propagated in $\mathrm{NB}$ at $35^{\circ} \mathrm{C}$ with shaking at $150 \mathrm{rpm}$ for $24 \mathrm{~h}$. Then $5 \mathrm{ml}$ inoculum of each bacterial isolate was transferred to sterilized mineral medium of $100 \mathrm{ml}$ using glucose $2 \%$ $(\mathrm{w} / \mathrm{v})$ as the carbon source and incubation was performed at $35^{\circ} \mathrm{C}$ with $150 \mathrm{rpm}$. The components of the mineral medium used was as follows $\left(\mathrm{g} \mathrm{L}^{-1}\right)$ : $\mathrm{NaCl}(0.01), \mathrm{KH}_{2} \mathrm{PO}_{4}$ (0.14), $\mathrm{CaCl}_{2} \cdot 2 \mathrm{H}_{2} \mathrm{O}(0.04), \mathrm{MgSO}_{4} \cdot 7 \mathrm{H}_{2} \mathrm{O}(0.6)$, $\mathrm{NaNO} 3$ (3.3), $\mathrm{FeSO}_{4} \cdot 7 \mathrm{H}_{2} \mathrm{O}(0.2), \mathrm{K}_{2} \mathrm{HPO}_{4}(2.2)$, and $0.5 \mathrm{ml}$ of trace element solution containing $\left(\mathrm{g} \mathrm{L}^{-1}\right): \mathrm{ZnSO}_{4} \cdot 7 \mathrm{H}_{2} \mathrm{O}(0.23), \quad \mathrm{MnSO}_{4} \cdot \mathrm{H}_{2} \mathrm{O}$ (0.178), $\mathrm{H}_{3} \mathrm{BO}_{3}(0.056), \mathrm{CuSO}_{4} \cdot 5 \mathrm{H}_{2} \mathrm{O}(0.1)$, $\mathrm{Na}_{2} \mathrm{MoO}_{4} \cdot 2 \mathrm{H}_{2} \mathrm{O} \quad(0.039), \quad \mathrm{CoCl}_{2} \cdot 6 \mathrm{H}_{2} \mathrm{O} \quad(0.04)$, $\mathrm{N}_{2} \mathrm{NiO}_{6} \cdot 6 \mathrm{H}_{2} \mathrm{O}(0.0004), \mathrm{KI}(0.066)$, and $\mathrm{Na}_{2}-$ EDTA (0.1). The $\mathrm{pH}$ of the mineral medium was maintained at $7.0 \pm 0.2$. Then the antagonistic bacteria were assessed for production of biosurfactant on the basis of reduction of surface tension (ST) of the culture medium, drop collapse, and emulsification stability $\left(E_{24}\right)$ test. All the screening tests were performed in triplicates.

ST measurement: ST was determined at 24,48 and $72 \mathrm{~h}$ of growth of the bacterial cultures. For this, the culture medium was centrifuged at 15,000 rpm for $10 \mathrm{~min}$. Then the cell pellet was removed, and ST of the supernatant was determined with a K11 tensiometer (Kruss, Hamburg, Germany) using the plate method. The bacteria capable of reducing the ST of the culture medium to $40 \mathrm{mN} \mathrm{m}^{-1}$ or less were identified as biosurfactant producers 
(Goswami et al. 2015).

Drop collapse test: This test was established by Jain et al. (1991), where destabilization of liquid droplets takes place due to the presence of surfactants. Glass slides were used for the test which were first dipped in hot water, ethanol, distilled water, and then allowed to dry. Crude oil of $15 \mu \mathrm{l}$ was put on the glass slide and next $10 \mu \mathrm{l}$ aliquot of supernatant from individual culture was then pipetted onto the slide. After $1 \mathrm{~min}$ the shape of the drop on the surface of oil was observed. The result was considered as negative, if the drop continued to be beaded, thus inferring the absence of biosurfactant in the culture. Whereas, if the drop gets collapsed, the result was considered as positive.

$E_{24}$ test: $E_{24}$ or the potential of biosurfactant to emulsify hydrocarbons was measured by mixing $2 \mathrm{ml}$ of the culture supernatant with 2 $\mathrm{ml}$ of a hydrocarbon (crude oil) in a graduated tube. Then vortexing of the mixture was performed at high speed for 2 min, which was then kept to get settle for $24 \mathrm{~h}$. $\mathrm{E}_{24}$ was determined by analysing the emulsion layer, which was stated in terms of the percentage of the total height of the mixture in the tube (Thivaharan \& Vytla 2013).

\section{Identification of rhizospheric biosurfactant producing bacteria}

The potent bacterium was then identified by $16 \mathrm{~S}$ rRNA gene sequencing for which the pure culture was grown in NB until log phase was accomplished (Kumar et al. 2016). The extraction of the genomic DNA from the culture was performed according to Bazzicalupo \& Fani (1996) and the extracted DNA was subjected to quality check and quantification. PCR amplification of 16S rRNA gene was carried out using the universal primers $8 \mathrm{~F}$ and 1492R. The amplicons were checked for quality and quantity (Mallick \& Chakraborty 2019). Sequencing of the amplicon was done using capillary electrophoresis with Sanger Big Dye Termination Chemistry (BDT v3.1 Cycle Sequencing Kit) that generated the forward and reverse sequences on ABI 3500 Genetic Analyzer. A consensus sequence of the $16 \mathrm{~S}$ region was generated from both the forward and reverse sequence data with aligner software. The generated 16S rRNA gene sequences were analyzed using Basic Local Alignment Search Tool (BLAST) in the NCBI GenBank to establish the identity of the bacterium. Twenty sequences were selected depending on maximum identity score and alignment of the sequences were carried out along with the present sequence in Clustal W using 16S rRNA gene of a Pseudomonas fluorescens strain as out group. Phylogenetic analyses of the isolate were performed in MEGAX and the phylogenetic tree was constructed with maximum likelihood method based on the Tamura-Nei model (1993). The bootstrap consensus tree inferred from 1000 replicates (Felsenstein 1985) was used to determine the evolutionary history of the taxa analysed.

Extraction and purification of biosurfactant from rhizospheric bacteria

Extraction of biosurfactant from bacterial cultures grown for $72 \mathrm{~h}$ was achieved by modifying the method depicted by Sarwar et al. (2018). At first centrifugation of the cultures was done at $4000 \mathrm{rpm}$ for $15 \mathrm{~min}$ at $4^{\circ} \mathrm{C}$. After that biosurfactants were acidified by adjusting $\mathrm{pH}$ of the culture supernatant to 2.0 with the addition of concentrated $\mathrm{HCl}$ which were then allowed to form precipitate at $4{ }^{\circ} \mathrm{C}$ overnight. Later, the precipitates were accumulated by centrifuging with $4000 \mathrm{rpm}$ for $15 \mathrm{~min}$ at $4^{\circ} \mathrm{C}$. Afterwards, lyophilization was performed at $-50^{\circ} \mathrm{C}$ for $24 \mathrm{~h}$. Methanol extraction of the lyophilized powder was done for $4 \mathrm{~h}$ and the extract was filtered through $0.45 \mu \mathrm{m}$ filter. Subsequently, the extract was evaporated to dryness using rotary evaporator (Sarwar et al. 2018).

Silica gel column chromatography of $60-120$ mesh was used to purify the crude biosurfactant (Goswami \& Deka 2019). For this, the column was packed with $50 \mathrm{~g}$ of activated slurry of silica and chloroform. Then crude biosurfactant of 1 
$\mathrm{g}$ was dissolved in methanol and was loaded into the column and elution was done stepwise using different solvent gradient consecutively. The order of solvent used were $100 \% \mathrm{CHCl}_{3^{\prime}}$ succeeded by a gradient of 95:5, 90:10, 75:25, 70:30, 50:50 (v/v) of $\mathrm{CHCl}_{3}: \mathrm{CH}_{3} \mathrm{OH}$ and lastly $100 \% \mathrm{CH}_{3} \mathrm{OH}$ (200 $\mathrm{ml}$ each) at a uniform flow rate of $2 \mathrm{~mL} \mathrm{Min}{ }^{-1}$. The fractions that contain biosurfactant were fused together and kept for drying under vacuum using a rotary evaporator at $40^{\circ} \mathrm{C}$.

\section{Qualitative analysis of purified biosurfactant}

The qualitative analyses of column purified biosurfactant were performed with LC-ESIMS by using the method as defined by Pathak \& Keharia (2014). The spectra were obtained across the mass range of $\mathrm{m} / \mathrm{z} 50-2,000$. The biosurfactant sample was injected into a Zorbax 300SB-C18 column (Santa Clara, CA, USA) (4.6 $9150 \mathrm{~mm}, 5 \mathrm{~lm}$ particle size) with $\mathrm{MeOH} /$ $\mathrm{H} 2 \mathrm{O} / 0.1 \%$ (v/v) formic acid on an Agilent 1100 HPLC system, coupled with HCT Ultra ETD II (Bruker Daltonics, Bremen, Germany) ion trap mass spectrometer in positive ion mode. Gradient of $80-95 \% \mathrm{MeOH}$ for $50 \mathrm{~min}, 95 \%$ $\mathrm{MeOH}$ for $5 \mathrm{~min}$ and $95-80 \% \mathrm{MeOH}$ for $5 \mathrm{~min}$ were pumped at a constant flow rate of 0.2 $\mathrm{mL} \mathrm{min}^{-1}$ with a run time of $60 \mathrm{~min}$. The data were achieved in an auto MS2 mode (Pathak \& Keharia 2014) by using collision-induced dissociation method for fragmentation. Final evaluation of the data was performed with the software Agilent Mass Hunter.

\section{Inhibitory effect of biosurfactant against \\ $P$. aphanidermatum}

\section{(a) Microtitre plates study}

This experiment was conducted in 96 well microtiter plate to evaluate the activities of biosurfactant against $P$. aphanidermatum spore. The influence of various concentrations of biosurfactant on the growth of $P$. aphanidermatum was assayed as depicted by Gudina et al. (2010) with few alterations. PDB was utilized to prepare the various concentrations of biosurfactant and the concentrations used were $0.1,0.2,0.3,0.4$, and $0.5 \mathrm{mg} \mathrm{mL}^{-1}(\mathrm{w} / \mathrm{v})$. Aliquot of $100 \mu \mathrm{L}$ from each concentration was transferred into alternative columns of the microtitre plate (Goswami et al. 2015). Controls were also included in the test in which PDB was used as positive control and PDB with spore was used as negative control. Spore suspension $\left(1 \times 10^{6}\right.$ spore $\left.\mathrm{mL}^{-1}\right)$ of $20 \mu \mathrm{L}$ was inoculated into all the wells of the plate except for the positive control. After covering the microplates, incubation was performed at $28 \pm 2^{\circ} \mathrm{C}$ for $48 \mathrm{~h}$. Percentage of growth inhibition at all the above biosurfactant concentrations (Goswami et al. 2015) along with the control well was assessed by analyzing the growth of $P$. aphanidermatum $\left(\mathrm{OD}_{600}\right)$ in a Microplate Reader (Bio-Rad, Model 680) (Borah et al. 2016).

\section{(b) Mycelium growth inhibition}

In this study, solutions of biosurfactant were prepared in Milli-Q water (w/v) using concentrations of $0.1,0.2,0.3,0.4$, and $0.5 \mathrm{mg}$ $\mathrm{mL}^{-1}$. Afterwards, $3.9 \mathrm{~g}$ of PDA was mixed to $100 \mathrm{~mL}$ of each of the concentrations of biosurfactant; sterilized and poured into Petri plates of $90 \mathrm{~mm}$ size. Control plates were set by adding simply PDA in Milli-Q water (Borah et al. 2016), i.e., without biosurfactant. To the middle of each plate mycelial plugs $(5 \mathrm{~mm}$ size) of $P$. aphanidermatum from 5 days old culture were individually transferred. Then incubation was performed at $28 \pm 2{ }^{\circ} \mathrm{C}$ for 10 days until the control plates were completely covered by mycelia. The mycelial growths of $P$. aphanidermatum in each plate were determined in reference to the diameters of the plate, and compared with control treatment (Goswami et al. 2014). The antagonistic activity was stated as inhibition of mycelial growth in percentage (Borah et al. 2016). The experiment was carried out in triplicates.

\section{Statistical analysis}

The data correspond to the arithmetical averages of three replicate values and the error bars denote the standard deviations. Results 
for determining the effect of the biosurfactant at different concentrations on the growth of $P$. aphanidermatum were evaluated by one-way analysis of variance (ANOVA) subsequent to least significant differences (LSD) test $(\mathrm{p}<0.05)$ (Goswami et al. 2015) using the Statistical Package SPSS Statistics v22.0 (IBM, Corp., United States).

\section{Results and discussion}

Selection of antagonistic bacterial strains

A total of 10 morphologically distinct probable antagonistic beneficial bacterial colonies, i.e., probiotics were isolated from rhizospheric soil of ginger plant following dilution plate method on NA plates. It was observed that all the colonies were discrete in shape, size, pigmentation, outer surface appearance etc. The individual bacterial colonies were picked up from NA plates. These were further preserved as pure cultures in NA slants and in nutrient broth which were retained at $4{ }^{\circ} \mathrm{C}$ for future use.

Dual culture test revealed that 5 out of the 10 rhizospheric bacterial isolates exhibited $>50 \%$
Table 1. In vitro screening of shortlisted ginger rhizobacteria for antagonism against Pythium aphanidermatum

\begin{tabular}{ll}
\hline Isolate no. & Inhibition $(\%)$ \\
\hline VS1 & $31.7 \pm 1.2$ \\
VS2 & $12.5 \pm 0.6$ \\
${ }^{*}$ VS3 & $58.0 \pm 1.3$ \\
${ }^{*}$ VS4 & $56.8 \pm 1.3$ \\
${ }^{*}$ VS5 & $65.1 \pm 0.7$ \\
VS6 & $12.9 \pm 1.2$ \\
"VS7 & $74.5 \pm 0.7$ \\
*VS8 & $63.9 \pm 1.3$ \\
VS9 & $29.8 \pm 0.7$ \\
VS10 & $24.7 \pm 1.2$ \\
Control & $0.0 \pm 0.0$ \\
\hline
\end{tabular}

Results are shown as mean \pm SD of three replicates *Selected bacterial isolates

inhibition of $P$. aphanidermatum by means of producing a zone of inhibition all around the bacterial colony on PDA which were then selected for further study (Table 1; Fig. 1). Raghavan et al. (2015) evaluated multi-trait PGPR for their disease suppressing and growth stimulating effects on ginger and suggested application of Bacillus amyloliquefaciens for

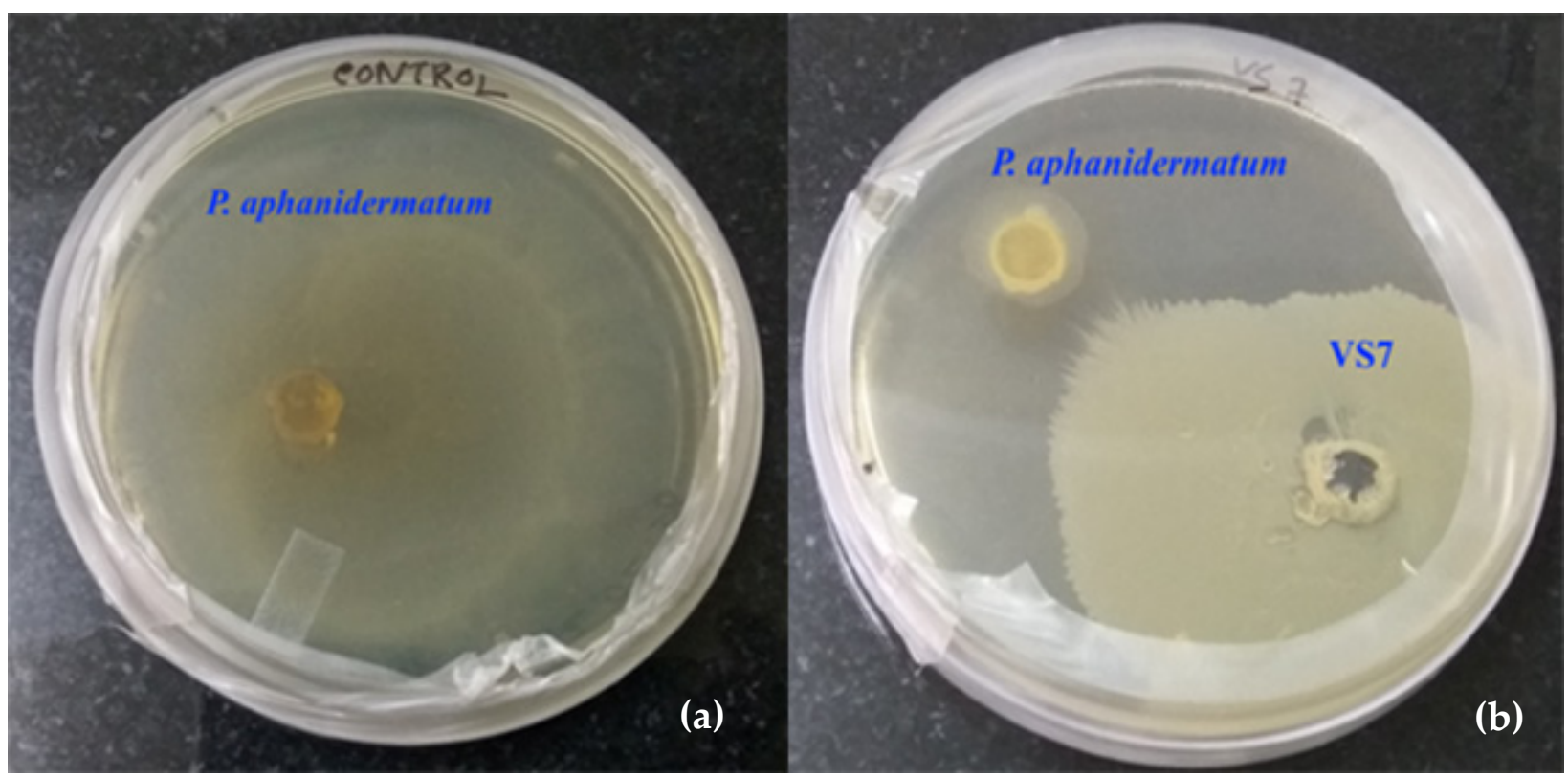

Fig. 1. Inhibition of soft rot pathogen Pythium aphanidermatum by the rhizospheric isolate VS7; (a) control (pathogen alone); (b) VS7 dual cultured with Pythium aphanidermatum. All plates were incubated at $28 \pm 2^{\circ} \mathrm{C}$ for 5 days (hyphal growth of $P$. aphanidermatum is transparent in appearance) 
nutrient and disease management in ginger. Kumar et al. (2016) reported biological control of Macrophomina phaseolina which causes Charcoal Rot in Vigna mungo using Enterococcus sp. BS13 that promotes plant growth.

\section{Screening of bacteria for biosurfactant production}

The bacterial isolates VS3, VS4, VS5, VS7 and VS8 were further tested for biosurfactant production employing ST measurement, drop collapse, and $\mathrm{E}_{24}$ test. The ST was measured using tensiometer by obtaining samples till 72 $\mathrm{h}$ of culture after a period of $24 \mathrm{~h}$ (Goswami et al. 2014). The isolate VS7 caused the maximum reduction in ST by $30.2 \mathrm{mN} \mathrm{m}^{-1}$ (Table 2). Highest reduction in ST was noticed $48 \mathrm{~h}$ after inoculation of the bacterial isolate. This is in agreement with Banat (1995) who implied that "for biosurfactant production microbes are anticipated to decrease ST of the culture medium to approximately $35 \mathrm{mN} \mathrm{m}^{-1 "}$. Jain et al. (1991) reported drop collapse as a sensitive and simple test to examine production of biosurfactant. In this study, it was observed that among all the bacterial isolates, only VS7 showed positive result (Table 2). The drop of the culture media collected from the isolate VS7 was collapsed within 1 min of placing it on the oil coated glass surface which showed the existence of biosurfactant in the culture media. According to Walter et al. (2010) the drop collapsed owing to the decrease of interfacial tension or the force amongst the hydrophobic surface and the liquid drop. While, the drops of other bacterial cultures remained intact and was in beaded form on oil coated surface. This occurred due to the hydrophobic nature of the oily surface for which the force initiated aggregation of the drop and the drop continued to be intact. This was found to be in conformity with the results stated by Viramontes-Ramos et al. (2010) that for a drop collapse test to be positive, a surface tension ought to be lesser than $45 \mathrm{mN} \mathrm{m}^{-1}$.

$\mathrm{E}_{24}$ test is an indirect technique to assess biosurfactant production. If the culture supernatant has biosurfactant then it would lead to emulsification of the existing hydrocarbons. A distinct emulsification activity with $86.30 \%$ of $\mathrm{E}_{24}$ was shown by the bacterial isolate VS7 in comparison to other isolates (Table 2). Nayarisseri et al. (2018) found highest emulsification activity (87\%) in the biosurfactant of Bacillus subtilis ANSKLAB03..

All these tests confirmed the isolate VS7 to be an effective biosurfactant producer and thus, it was preferred for further studies.

\section{Identification of potent bacteria}

The 16S rRNA sequence of the bacterial isolate VS7 showed $100 \%$ homology with Bacillus altitudinis strain 41KF2b (GenBank Accession Number: NR042337.1). 16S rRNA sequence

Table 2. Surface tension $\left(\mathrm{mN} \mathrm{m}^{-1}\right)$, drop-collapse test, and emulsification index (\%) of the bacterial isolates

\begin{tabular}{|c|c|c|c|c|c|c|}
\hline \multirow[t]{2}{*}{ Isolate No. } & \multicolumn{4}{|c|}{ Surface tension $\left(\mathrm{mN} \mathrm{m}^{-1}\right)$} & \multirow{2}{*}{$\begin{array}{c}\text { Drop } \\
\text { collapse test }\end{array}$} & \multirow{2}{*}{$\mathrm{E}_{24}(\%)$} \\
\hline & $0 \mathrm{~h}$ & $24 \mathrm{~h}$ & $48 \mathrm{~h}$ & $72 \mathrm{~h}$ & & \\
\hline Control & $70.3 \pm 0.30$ & $70.7 \pm 0.20$ & $70.7 \pm 0.26$ & $70.4 \pm 0.20$ & - & $0.0 \pm 0.00$ \\
\hline VS3 & $59.1 \pm 0.21$ & $56.3 \pm 0.35$ & $50.5 \pm 0.35$ & $50.4 \pm 0.35$ & - & $38.70 \pm 0.20$ \\
\hline VS4 & $64.5 \pm 0.45$ & $57.5 \pm 0.35$ & $51.1 \pm 0.30$ & $50.8 \pm 0.15$ & - & $39.28 \pm 0.20$ \\
\hline VS5 & $71.6 \pm 0.31$ & $70.6 \pm 0.25$ & $70.1 \pm 0.31$ & $67.0 \pm 0.21$ & - & $28.48 \pm 0.24$ \\
\hline VS7 & $59.3 \pm 0.25$ & $40.5 \pm 0.21$ & $30.2 \pm 0.25$ & $35.9 \pm 0.31$ & + & $86.30 \pm 0.40$ \\
\hline VS8 & $66.6 \pm 0.31$ & $62.5 \pm 0.25$ & $56.7 \pm 0.25$ & $53.6 \pm 0.25$ & - & $34.85 \pm 0.40$ \\
\hline
\end{tabular}

Results are shown as mean \pm SD of three replicates. Drop collapse test and $\mathrm{E}_{24}(\%)$ were performed after 48 $\mathrm{h}$ of growth of the bacterial isolates in mineral medium

*Bacterial isolate producing biosurfactant 


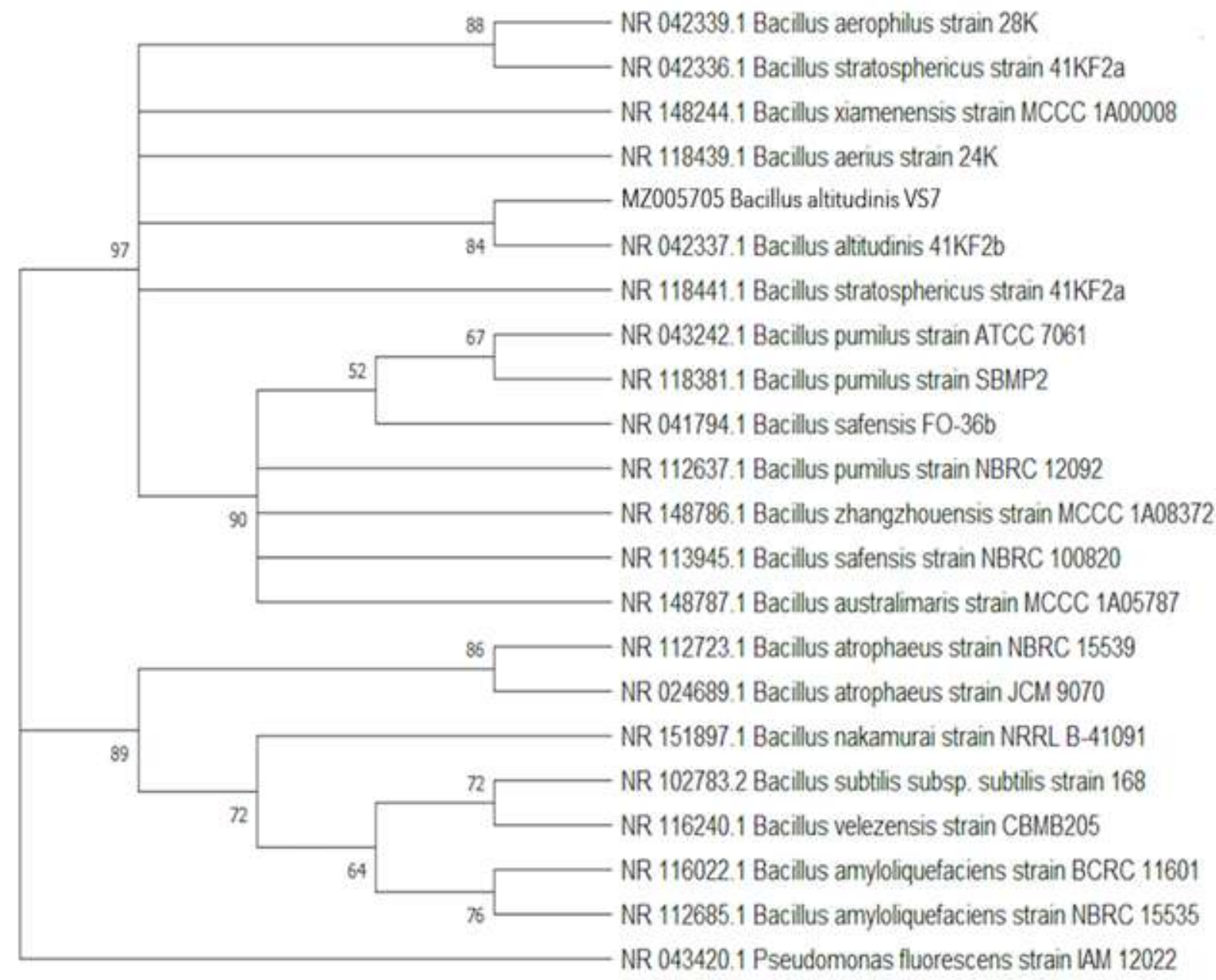

Fig. 2. Phylogenetic analysis of the rhizobacterium Bacillus altitudinis VS7 showing its position among related members of the genus Bacillus (Pseudomonas fluorescens strain was kept as outgroup).The analyses were conducted in MEGA X

of the isolate VS7 were submitted to NCBI GenBank database under the accession number MZ005705. Phylogenetic tree also showed close clustering of VS7 with isolates of B. altitudinis (Fig. 2).

Analysis of biosurfactant produced by the rhizobacterium B. altitudinis VS7

The corresponding mass spectra obtained from the LC-ESI-MS characterization of purified biosurfactant sample indicated the occurrence of two major compounds at $\mathrm{m} / \mathrm{z}$ 1021.78 and 1064.7 that may be regarded as surfactin isoforms from the existing literature. Conferring to our results, the observed peaks with $\mathrm{m} / \mathrm{z}$ ratios of 1021.78 and 1064.7 matched to compounds corresponding to the family of surfactin and denoted homologues comprising $\mathrm{C}_{14}$ and $\mathrm{C}_{17}$ acyl chains respectively (Sarwar et al. 2018). Same molecular masses have been reported by Goswami \& Deka (2019) with cyclic lipopeptide, i.e. surfactin in their study on production of biosurfactant by the rhizosphere bacteria Bacillus altitudinis MS16. The observed $\mathrm{m} / \mathrm{z}$ values in our study were also coherent with the results reported by Pathak \& Keharia (2013) in their work on characterization of fungal antagonistic bacilli and identification of the metabolites responsible for their antifungal activity. In support of the characteristic peak of surfactin the MS chromatograms are shown in Fig. 3(a, b). 


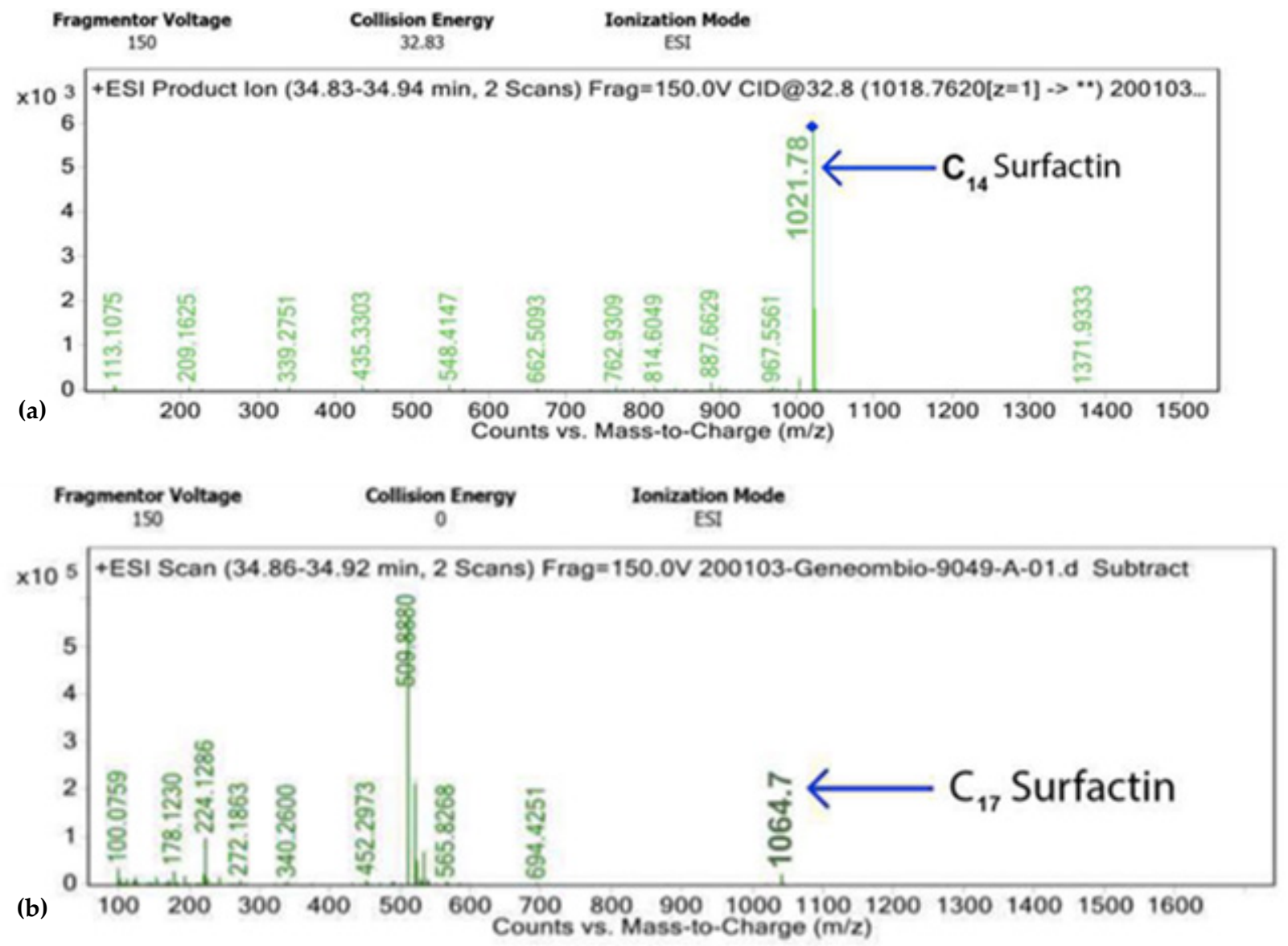

Fig. 3. LC-ESI-MS analysis of methanolic extract of biosurfactant obtained from Bacillus altitudinis VS7 in positive ion mode. Mass Spectra (ESI+) showing peak of molecular ions with m/z of (a) 1021.78 and (b) 1064.7

Therefore, it can be deduced from LC-ESI-MS analysis that the biosurfactant synthesized by B. altitudinis VS7 is a surfactin like compound, a cyclic lipopeptide based on their molecular masses. Surfactin homologues also have remarkable interfacial properties and inclined as effective hydrocarbon solubilizers, viscous reducers, and metal sequesters which have wide application in bioremediation and environment protection (Goswami \& Deka 2019).

\section{Effect of biosurfactant on P. aphanidermatum}

\section{(a) Microtitre plates study}

Significant spore inhibitions of 56.1, 61.2, 65.7, 70.9 and $75.3 \%$ were achieved with biosurfactant concentrations of $0.1,0.2,0.3,0.4$, and $0.5 \mathrm{mg} \mathrm{mL}^{-1}$ respectively (Table 3).

\section{(b) Mycelium growth inhibition}

Significant mycelial inhibitions of 35.3, 41.6, $45.9,50.6$ and $55.8 \%$ were obtained with biosurfactant concentrations of $0.1,0.2,0.3,0.4$, and $0.5 \mathrm{mg} \mathrm{mL}^{-1}$ respectively (Table 3 ).

Le et al. (2014) reported Trichoderma spp. as the extensively applied biocontrol agent to control soft rot in ginger. In dual culture assays, together with Trichoderma spp., a number of rhizobacteria were similarly found to be antagonistic and exhibited substantial inhibition of the pathogen (Bhaiet al.2005). They reported that by dipping seed in a solution of Bacillus sp. or Pseudomonas fluorescens $\left(10^{8} \mathrm{CFU}\right.$ $\mathrm{mL}^{-1}$ ) for $1 \mathrm{~h}$ (Le et al. 2014) in combination with 
Table 3. Percent inhibition of spore and mycelial growth of Pythium aphanidermatum after application of biosurfactant obtained from Bacillus altitudinis VS7 at different concentrations ( $\mathrm{mg} \mathrm{mL}^{-1}$ )

\begin{tabular}{ccc}
\hline $\begin{array}{c}\text { Biosurfactant conc. } \\
\left(\mathrm{mg} \mathrm{mL}^{-1}\right)\end{array}$ & $\begin{array}{c}\text { Spore inhibition } \\
(\%)\end{array}$ & $\begin{array}{c}\text { Mycelial growth } \\
\text { inhibition }(\%)\end{array}$ \\
\hline 0.1 & $56.1 \pm 0.70$ & $35.3 \pm 0.60$ \\
0.2 & $61.2 \pm 0.35$ & $41.6 \pm 0.40$ \\
0.3 & $65.7 \pm 0.30$ & $45.9 \pm 0.65$ \\
0.4 & $70.9 \pm 0.40$ & $50.6 \pm 0.40$ \\
0.5 & $75.3 \pm 0.40$ & $55.8 \pm 0.40$ \\
\hline
\end{tabular}

Results are statistically significant (ANOVA, LSD; $P<0.05$ ) and expressed as mean \pm SD of values obtained from three replications

Glomus sp. before planting resulted in disease suppression, thus working as a bioprotectant. However, our study describes the first information regarding the antagonistic activity of biosurfactant generated by a rhizobacterium, i.e. B. altitudinis VS7 against P. aphanidermatum. Besides, the growth rate inhibition was observed with very low concentration of biosurfactant extracted from B. altitudinis VS7, which indicates its efficacy to control soft rot of ginger caused by $P$. aphanidermatum. Goswami \& Deka (2019) stated that the lipopeptide biosurfactant from the rhizosphere bacteria $B$. altitudinis MS16 caused significant antifungal activity against Colletotrichum gloeosporioides and Sclerotinia sclerotiorum. It is a well-established fact that the lipopeptide biosurfactants can initiate formation of pores in the lipid bilayer of the target pathogen thus destabilizing the membranes and disturbing its integrity and permeability. The formation of pores may cause in transmembrane ion influxes that eventually disrupts membrane bilayer triggering cell death (Mangoni \& Shai 2011).

From both microtitre plate and mycelium growth inhibition study, it was perceived that the activity of biosurfactant from $B$. altitudinis VS7 was more effective against spores in comparison to the activity against mycelia. This result was found to be similar as reported by Borah et al. (2016) for antifungal effect of biosurfactant from Pseudomonas aeruginosa SS14 against Fusarium verticillioides, where a high concentration was needed to suppress the growth of mycelia compared to that of the spores. Feofilova et al. (2015) stated that this variance could be owing to the dissimilarities in composition amongst the cell walls of spores and mycelia.

\section{Conclusion}

The current investigation has demonstrated the prospect of biosurfactants obtained from the rhizobacterium B. altitudinis VS7 for use as biopesticides to control soft rot of ginger caused by $P$. aphanidermatum. This is the first report depicting the application of biosurfactant against soft rot of ginger. But field trials would be required to establish its practical applicability.

\section{Acknowledgements}

The authors are grateful to the Head, Department of Biochemistry, North-Eastern Hill University, Shillong, Meghalaya, India for affording all the provision for carrying out the research work. Debahuti Goswami acknowledges DST-SERB, Govt. of India for granting National Post-Doctoral Fellowship. Authors would also like to thank Geneombio Technologies Pvt. Ltd., Pune, India for investigating samples using LC-ESI-MS. We also thank Santosh Vishwakarma, Bioinformatics Centre, North-Eastern Hill University, Shillong, Meghalaya, India for assisting in performing phylogenetic analysis. 


\section{References}

Banat I M 1995 Biosurfactants production and possible uses in microbial enhanced oil recovery and oil pollution remediation: a review. Bioresour. Technol. 51: 1-12.

Bazzicalupo M \& Fani R 1996 The use of RAPD for generating specific DNA probes for microorganisms. Methods Mol. Biol. 50: 155175.

Bhai R S, Kishore V K, Kumar A, Anandaraj M \& Eapen S J 2005 Screening of rhizobacterial isolates against soft rot disease of ginger (Zingiberofficinale Rosc.). JOSAC. 14: 130-136.

Borah S N, Goswami D, Sarma H K, Cameotra S S \& Deka S 2016 Rhamnolipid Biosurfactant against Fusarium verticillioides to Control Stalk and Ear Rot Disease of Maize. Front. Microbiol. 7: 1505.

Dake G N \& Edison S 1989 Association of pathogens with soft rot of ginger in Kerala. Indian Phytopathol. 42: 116-119.

Felsenstein J 1985 Confidence limits on phylogenies: An approach using the bootstrap. Evolution. 39: 783-791.

Feofilova E P, Sergeeva Y E, Mysyakina I S \& Bokareva D A 2015 Lipid composition in cell walls and in mycelial and spore cells of mycelial fungi. Microbiology. 84: 170-176.

Gosal S K, Kaur J, Kaur J 2017 Plant GrowthPromoting Rhizobacteria: A Probiotic for Plant Health and Productivity. In: Kumar V, Kumar M, Sharma S, \&Prasad R (Eds.) Probiotics and Plant Health. Springer, Singapore. https://doi.org/10.1007/978-98110-3473-2_27.

Goswami D, Borah S N, Lahkar J, Handique P J \& Deka S 2015 Antifungal properties of rhamnolipid produced by Pseudomonas aeruginosa DS9 against Colletotrichum falcatum. J. Basic Microbiol. 55: 1265- 1274.

Goswami D, Handique P J \& Deka S 2014 Rhamnolipid biosurfactant against Fusarium sacchari-the causal organism of pokkahboeng disease of sugarcane. J. Basic Microbiol. 54: 548-557.

Goswami M \& Deka S 2019 Biosurfactant production by a rhizosphere bacteria Bacillus altitudinis MS16 and its promising emulsification and antifungal activity. Colloids Surf. B. 178: 285296.

Gudina E J, Rocha V, Teixeira J A \& Rodrigues L R 2010 Antimicrobial and antiadhesive properties of a biosurfactant isolated from Lactobacillus paracaseissp. paracaseiA20. Lett. Appl. Microbiol. 50: 419-424.

Jain D K, Collins-Thompson D L, Lee H \& Trevors J T 1991 A drop-collapsing test for screening surfactant-producing microorganisms. J. Microbiol. Methods. 13: 271-279.

Kavitha P G \& Thomas G 2007 Evaluation of Zingiberaceae for resistance to ginger soft rot caused by Pythium aphanidermatum (Edson) Fitzp. Plant Gent. Resorc. News Lett. 152: 5457.

Kumar S, Dubey R C \& Maheshwari D K 2016 Biosurfactant-Mediated Biocontrol of Macrophomina phaseolina Causing Charcoal Rot in Vigna mungo by a Plant Growth Promoting Enterococcus sp. BS13. J. Plant Pathol. Microbiol. 7: 385.

Le D P, Smith M, Hudler G W \& Aitken E 2014 Pythium soft rot of ginger: Detection and identification of the causal pathogens, and their control. Crop Prot. 65: 153-167.

Mahanta J \& Samajdar T 2013 Diseases of Ginger, Krishi Vigyan Kendra, Tura, Meghalaya.

Malfanova N, Kamilova F, Validov SH, Shcherbakov A, Chebotar V, Tikhonovich I \& Lugtenberg B 2011 Characterization of Bacillus subtilis HC8, a novel plant-beneficial endophytic strain from giant hogweed. Microb. Biotechnol. 4: 523-532.

Mallick S K, Chakraborty S 2019 Bioremediation of wastewater from automobile service station in anoxic-aerobic sequential reactors and microbial analysis. Chem. Eng. J. 361: 982989.

Mangoni M L \& Shai Y 2011 Short native antimicrobial peptides and engineered ultrashort lipopeptides: similarities and differences in cell specificities and modes of action. Cell Mol. Life Sci. 68: 2267.

Nayarisseri A, Singh P \& Singh S K 2018 Screening, isolation and characterization of biosurfactant producing Bacillus subtilis strain ANSKLAB03. Bioinformation. 14: 304314. 
Ongena M, Jacques P, Toure Y, Destain J, Jabrane A \& Thonart P 2005 Involvement of fengycintype lipopeptides in the multifaceted biocontrol potential of Bacillus subtilis. Appl. Microbiol. Biotechnol. 69: 29-38.

Pathak K V \& Keharia H 2013 Characterization of fungal antagonistic bacilli isolated from aerial roots of banyan (Ficus benghalensis) using intact-cell MALDI-TOF mass spectrometry (ICMS). J. Appl.Microbiol. 114:1300-1310.

Pathak K V \& Keharia H 2014 Identification of surfactins and iturins produced by potent fungal antagonist, Bacillus subtilis K1 isolated from aerial roots of banyan (Ficus benghalensis) tree using mass spectrometry. 3 Biotech. 4: 283-295.

Raghavan D, Muthuswamy A, Kumar A, Bini Y K, Subila K P \& Aravind R 2015 Isolation, characterization and evaluation of multitrait plant growth promoting rhizobacteria for their growth promoting and disease suppressing effects on ginger. Microbiol. Res. 173: 34-43.

Rahman P K S M \& Gakpe E 2008 Production, characterization and applications of biosurfactants-review. Biotechnol. 7: 360-370.

Sarma Y R 1994 Rhizome rot disease of ginger and turmeric. In: Chadha K L \& Rethinam P (Eds.) Advances in Horticulture. Plantation and Spices Crops, Part-2 (pp. 1113-1138). Malhotra Publication House, New Delhi.

Sarwar A, Brader G, Corretto E, Aleti G,
Abaidullah M, Sessitsch A \& Hafeez F Y 2018 Qualitative analysis of biosurfactants from Bacillus species exhibiting antifungal activity. PLoS One. 13: e0198107.

ShekharS, SundaramanickamA\&BalasubramanianT 2015 Biosurfactant Producing Microbes and their Potential Applications: A Review. Crit. Rev. Env. Sci. Tec. 45: 1522-1554.

Sumbhe A \& Tomar A 2015 Symbiotic organisms: Key for plant growth promotion. International Journal of Science, Engineering and Technology Research (IJSETR). 4: 4.

Tamura K \& Nei M 1993 Estimation of the number of nucleotide substitutions in the control region of mitochondrial DNA in humans and chimpanzees. Mol. Biol. Evol. 10: 512-526.

Thivaharan V \& Vytla R M 2013 Production of a Lipopeptide Biosurfactant by a Novel Bacillus sp. and Its Applicability to Enhanced Oil Recovery. ISRN. Microbiology. 2013: Article ID 621519, 8 pages.

Viramontes-Ramos S, Portillo-Ruiz M C, BallinasCasarrubias M D L, Torres-Munoz J V, Rivera-Chavira B E \& Nevarez-Moorillon G V 2010 Selection of biosurfactant/bioemulsifierproducing bacteria from hydrocarbon contaminated soil. Braz. J. Microbiol. 41: 668675 .

Walter V, Syldatk C \& Hausmann R 2010 Screening concepts for the isolation of biosurfactant producing microorganisms. Adv. Exp. Med. Biol. 672: 1-13. 